\title{
Ferritina. Factibilidad e importancia de su medición
}

Ferritin. Feasibility and importance of its measurement

\section{Sr. Editor:}

En la última década del siglo pasado la Organización Mundial de la Salud (OMS) estimó que más del 30\% de la población mundial tiene anemia, en su mayoría debido a la deficiencia de hierro $(\mathrm{DH})^{(1)}$. La deficiencia de hierro se produce a través de un largo periodo de tiempo, permitiendo que la depleción de los depósitos de hierro se realice progresivamente trayendo como consecuencia la anemia ${ }^{(2)}$ por deficiencia de hierro o llamada también anemia ferropénica ${ }^{(3)}$.

La suplementación con hierro, sea por micronutrientes, sulfato ferroso y últimamente hierro polimaltosado, se viene practicando en el Perú y en muchos otros países con prevalencias de anemia moderada y alta, por recomendaciones de la Organización Mundial de la Salud ${ }^{(4)}$; sin embargo, la prevalencia de anemia en niños no experimentó diferencias significativas en el periodo 2014 a $2019^{(5)}$.

La concentración de ferritina es un buen marcador de las reservas de hierro ${ }^{(3)} \mathrm{y}$ debe usarse para diagnosticar la deficiencia de hierro en personas aparentemente sanas ${ }^{(6)}$, pero para una adecuada interpretación - en caso de sospecha de cuadro inflamatorio agudo - el punto de corte del valor de ferritina sérica se reajusta según el resultado de la medición de proteína $\mathrm{C}$ reactiva ${ }^{(3,6)}$.
La medición ferritina y proteína $\mathrm{C}$ reactiva son procedimientos contemplados dentro del tarifario de procedimientos médicos y sanitarios del Seguro Integral de Salud (SIS), para el segundo y tercer nivel de atención de salud y para las personas aseguradas al SIS, todos los procedimientos contemplados son gratuitos y garantizados por el mismo ${ }^{(7)}$.

La ferritina se puede medir usando ensayos radiométricos, no radiométricos y de aglutinación. Ningún método parece ser superior a otro y todos los métodos son aceptables si se utiliza un material conmutable trazable al estándar de referencia internacional de la OMS para calibrar el ensayo ${ }^{(6)}$.

La inmunoturbidimetria es un sub método dentro de los métodos de aglutinación mencionado por la OMS para su determinación ${ }^{(8)}$ y puede realizarse en analizadores bioquímicos automatizados que se cuentan en los hospitales del segundo y tercer nivel de atención. La Norma Técnica de Salud para el manejo terapéutico y preventivo de la anemia en niños, adolescentes, mujeres gestantes y puérperas señala que en los establecimientos de salud que cuenten con disponibilidad se podrá solicitar ferritina sérica ${ }^{(3)}$. La medición de ferritina se usa cuando la anemia persiste sin evolución favorable, a pesar de haber iniciado el tratamiento y contar con una buena adherencia al suplemento, si es normal la causa de la anemia no es la falta de hierro ${ }^{(3)}$.

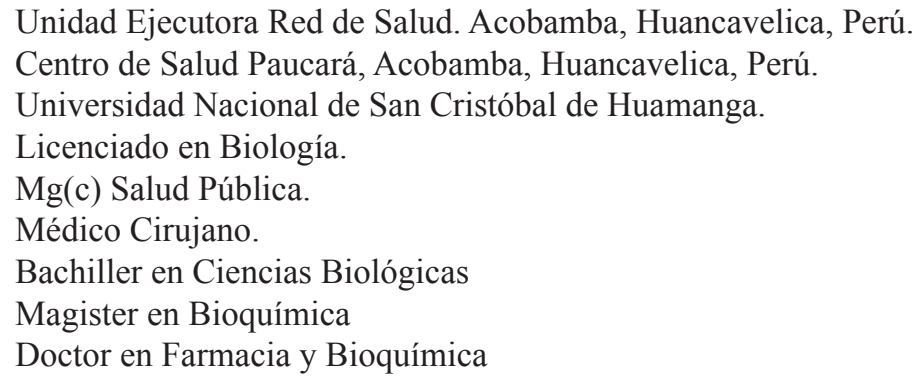


La concentración de ferritina puede usarse para monitorear y evaluar el impacto de las intervenciones sobre el estado del hierro ${ }^{(6)}$, por tanto, se sugiere la implementación de este marcador para el primer nivel de atención de salud donde se agudiza la prevalencia de anemia en niños.

John Christian Chávez-Barriga ${ }^{1, a, b}$, Hardy Esplana-Boza ${ }^{1, \mathrm{c}}$, Banesa Janampa-Coras ${ }^{2, \mathrm{~d}}$, Jose Alejandro Yarleque-Mujica ${ }^{3, e, f}$

\section{Correspondencia:}

John Christian Chávez Barriga

Coronel Cisneros $\mathrm{S} / \mathrm{N}$ - Sapallanga

Huancayo, Junín, Perú

Correo electrónico: aguilatlv@hotmail.com

Teléfono 511-990087880

\section{REFERENCIAS BIBLIOGRÁFICAS}

1. Auerbach M, Adamson JW. How we diagnose and treat iron deficiency anemia. Am J Hematol. 2016; 91(1):31-8. DOI: 10.1002/ajh.24201

2. Quezada N. Texto de Hematologia Clínica. Lima: Fondo Editorial Comunicacional del Colegio Médico del Perú; 2017.

3. Ministerio de Salud. Norma Técnica de Salud 134-MINSA/2017/DGIESP. Norma Técnica de Salud para el manejo terapéutico y preventivo de la anemia en niños, adolescentes, mujeres gestantes y puérperas. Lima, Perú: Ministerio de Salud; 2016. (Citado el 20 de diciembre de 2020) Disponible en: http://bvs.minsa.gob.pe/local/ MINSA/4190.pdf
4. World Health Organization. Iron deficiency anaemia: assessment, prevention and control A guide for programme managers. Ginebra: World Health Organization; 2001. (Citado el 20 diciembre de 2020) Disponible en: https://www.who.int/ nutrition/publications/micronutrients/anaemia iron_deficiency/WHO_NHD_01.3/en/

5. Instituto Nacional de Salud. Sistema de Información del Estado Nutricional. Informes 2018 - 2019. Lima: Instituto Nacional de Salud; 2019. (Citado el 20 de diciembre de 2020) Disponible en: https:// web.ins.gob.pe/es/alimentacion-y-nutricion/ vigilancia-alimentaria-y-nutricional/vigilanciadel-sistema-de-informacion-del-estadonutricional-en-\%20EESS

6. World Health Organization. WHO guideline on use of ferritin concentrations to assess iron status in individuals and populations. Geneva: World Health Organization; 2020. (Citado el 20 de diciembre de 2020). Disponible en: https://apps. who.int/iris/handle/10665/331505

7. Ministerio de Salud. Resolución Jefatural $\mathrm{N}^{\circ}$ 017-2019/SIS Tarifario de Procedimientos Médicos y Sanitarios del Seguro Integral de Salud. Lima: Ministerio de Salud; 2019. (Citado el 20 de diciembre de 2020) Disponible en: https://cdn. www.gob.pe/uploads/document/file/1264405/ RJ2019_017.pdf

8. World Health Organization|. Serum ferritin concentrations for the assessment of iron status and iron deficiency in populations. Ginebra: World Health Organization; 2011. Disponible en: https:// apps.who.int/iris/handle/10665/85843

Recibido: 28/12/2020

Aceptado: 30/03/2021 